\title{
The Influence of Time Landmarks on Consumers' Advertising Appeal Preferences
}

\author{
Chunxiu Ye, Hong Zhou \\ School of Management, Jinan University, Guangzhou, China \\ Email:m-forever@live.cn, $18106586 @ q q . c o m$
}

How to cite this paper: Ye, C. X., \& Zhou, H. (2019). The Influence of Time Landmarks on Consumers' Advertising Appeal Preferences. Psychology, 10, 560-577. https://doi.org/10.4236/psych.2019.104036

Received: February 26, 2019

Accepted: March 16, 2019

Published: March 19, 2019

Copyright $\odot 2019$ by author(s) and Scientific Research Publishing Inc. This work is licensed under the Creative Commons Attribution International License (CC BY 4.0).

http://creativecommons.org/licenses/by/4.0/

\section{c) (i) Open Access}

\begin{abstract}
As one of the main carriers of corporate product promotion-advertising plays a vital role, and advertising always contains the words of time landmarks or the time landmarks embedded in its content, so this article from the two major advertising The constituent elements-time landmarks (fresh/ ending) and the type of advertising appeal (emotional/rational appeal), start to study the influence of time landmarks on the preference of consumers' advertising appeals. This study explores the impact of time landmarks on consumer preference type's preferences through two experiments, and studies the mediating role of self-depletion perception. Consumers who activate the fresh time landmarks prefer a rational advertising appeal, while consumers who activate the ending time landmarks prefer an emotional advertising appeal.
\end{abstract}

\section{Keywords}

Time Landmarks, Type of Advertising Appeal, Ego-Depletion, Dual-Processing Theory

\section{Introduction}

Time is one of the most important environmental variables and has a significant impact on consumer perception and behavior (Goldenberg et al., 2000), while time landmarks are an environmental clue in everyday shopping life.

Advertisements often contain fresh time landmarks or ending time landmarks. By stimulating the words or prompting the words to activate the consumer's perception of different time landmarks, the consumer is likely to enter the situation indicated by the time mark, and the situation. It determines whether the emotional or cognitive pathway is most convincing to consumers (Pham \& Avnet, 2004), which may result in consumers' preferences for the type 
of emotional or rational advertising appeals.

Activating consumer perceptions of time landmarks may give consumers different preferences for rational or emotional advertising appeals. In the activation of real time landmarks, such as Youku platform, in the advertisement with the word "year of the beginning", the "original IP professional team" and the "exclusive notice, tidbit, barrage" and other platform features are emphasized. Advertising appeals while in the "year-end" advertising style is biased, such as the copy "this world, some busy; this world, some lonely; this world, some dreams; this world, some casual; this world, very Youku.", etc., is an emotional advertising appeal that allows consumers to have emotional connections to Youku platform. When activating a situational time landmarks, for example, a car advertisement often hides time landmarks such as sunrise and night. When an activation time landmarks such as sunrise is activated in an advertisement, the advertisement often advertises the performance of the car. Rational advertising appeals for product characteristics such as power and handling stability; and when an ending time landmarks such as night is activated in an advertisement, the advertisement may advertise the car to make people's nightlife more colorful or "night, bring you back to comfort "Home" and other emotional advertising appeals.

Therefore, this study attempts to explore the consumer's preference for rational or emotional advertising appeals under the activation fresh or ending time landmarks. Furthermore, this study will delve into the psychological mechanism of time landmarks on consumer advertising appeal preferences, and that different time landmarks in all decision scenarios will have different preferences for consumer advertising appeal types, then the boundary conditions are what is it?

This study is mainly divided into five chapters. The first chapter is the introduction; it focuses on the background of this research and the basic structure of the article. The second chapter is the literature review, sorting and summarizing the time landmarks, ego-depletion and dual-processing theory. The third chapter is mainly based on the theory of previous literature, around the research. The research ideas construct the theoretical model. The fourth chapter is the experimental design. By designing different experimental materials, the different variables are manipulated to explore the deep mechanism of action behind the phenomenon. The fifth chapter is the research conclusion, which is mainly combined with the data in Chapter 4. It analyzes the results, summarizes the relevant research conclusions, and proposes management recommendations and research limitations.

\section{Theoretical Background}

\subsection{Time Landmarks}

Some scholars have divided the time landmarks into a fresh time landmarks and an ending time landmarks for the reference time node on the calendar. The fresh time landmarks refers to the time point that enables people to perceive the 
"fresh", such as: morning, Monday, early month, early year, etc. (Dai, Milkman et al., 2014), corresponding to the ending time landmarks means that it can The time at which people perceive "ending", such as: evening, weekend, end of month, year-end, etc. (Alter \& Hershfield, 2014).

This study is based on the ordinary calendar time landmarks and the situational time landmarks instead of the special special time landmarks, focusing on the different influences of the activation fresh time landmarks and the ending time landmarks on the consumer information type preference.

Time is one of the most important environmental variables and has a significant impact on consumer perception and behavior (Goldenberg et al., 2000), while time landmarks are an environmental clue in everyday life. The fresh time landmarks indicates that the beginning of a period of time can enable people to generate a sense of time about the beginning; and the ending time landmarks predicts the end of a period of time, enabling people to generate a sense of time about the end. Obviously these two time landmarks will have an impact on consumers.

Previous studies have found that time landmarks can influence consumers' moral behavior, healthy choices, and self-improvement behaviors by comparing individual behavioral differences at different time points. In the study of the fresh time landmarks, individuals at the beginning time have more self-control ability and tend to make more ethical behavior than the normal time point (Kouchaki \& Smith, 2014); at some point in time Beginning time landmarks and special time landmarks (such as the beginning of the year, birthday or holiday), consumers will show more ambitious behavior (Dai, Milkman et al., 2014), such as more active in weight loss, alcohol and health Lifestyle and other lifestyles (Khan \& Dhar, 2007; Shiv \& Fedorikhin, 1999). In the study of ending-time landmarks, ending-time landmarks can motivate consumers to review the past (Alter \& Hershfield, 2014), as individuals need to accumulate enough physical and mental energy to self-regulate and control (Baumeister et al., 2008), Therefore, the ending time landmarks also has an impact on the individual's self-control behavior.

At present, the impact of time landmarks on consumer behavior has not been related to its influence on information appeal preferences. The study found that when individuals imagine themselves performing a series of information processing activities, they will perform poorly in subsequent inference and judgment tasks (Barden \& Petty, 2008), while activating the perception of ending time landmarks. People's psychological resource exhaustion perception will be significantly enhanced (Zhang Ziqi, Pang Wei, Liu Xiaomei, 2017), then the cognitive level of individuals when they activate different time landmarks may also be different, so that individual information about emotional appeals and rational appeal information may exist. The difference in preferences, so this paper intends to explore the impact of time landmarks on consumer advertising appeal type preferences.

Unlike other physical and sensory dimensions, time is truly ubiquitous, all 
stimuli and activities have time horizons, and time perception is a universal experience (Grondin, 2001; Lloyd \& Arstila, 2014). Unlike other basic dimensions, time has no specialized sensory organs. On the contrary, psychological time is an abstraction, a structure or incidental phenomenon in which our thinking operates, and it infiltrates our consciousness experience in some way. The judgment of time is almost at the core of all individual behaviors, that is, our subjective attitude towards time can explain the coherence of events (Grondin, 2010).

Special time landmarks will give consumers a stronger motivation to selfimprove, motivating consumers to develop motivations for life and the pursuit of ideal self (Ersnerher shfield et al., 2009; Koo \& Fishbach, 2008; Oettingen et al., 2009).

Consumer perception of different time landmarks can affect an individual's perception of self-control resources and psychological resources. On the one hand, individuals at the beginning of time have more self-control capabilities (Kouchaki \& Smith, 2014), while individuals with higher self-control levels have more self-control resources. On the other hand, compared to the fresh time landmarks, when people activate the perception of the ending time landmarks, people's perceived psychological resource exhaustion is significantly greater (Shang, Pang, \& Liu, 2017).

\subsection{Ego-Depletion}

Baumeister et al. (1998) describe the phenomenon of Ego-depletion: "The phenomenon of self-performing will or ability to temporarily decline, including the ability to control the environment, control the self, make decisions, and initiate behaviors."

Clarkson, Hirt et al. (2010) further explain and demonstrate Ego-depletion perception. They believe that the perception of loss is an important component of resource loss. People's perception of loss depends not only on the actual loss state of the individual. Also affected by the contextual attribution information provided. People often use contextual cues to inform or explain their internal state (Ross, 1989). Individuals are affected by situational attribution, and their perceived loss states may differ from actual losses. The perception of loss can come from feedback operations, and Independent of a person's actual loss state. Muraven \& Slessareva (2003) found that ego-depletion can be a motivational flaw rather than a lack of resources. Clarkson, Hirt et al. (2010) found that in the sequential task paradigm, the perception of resource loss is more predictive of performance patterns than the actual loss, suggesting that the ego-depletion effect may be driven by subjective perception rather than a reduction in resources. In other words, people's perception of Ego-depletion and real ego-depletion will produce a series of aftereffects that affect people's perceptions and behaviors.

Human body activities need to rely on their vitality, and the decline or lack of vitality will directly affect the normal operation of the body. Similarly, a large number of human behaviors in social adaptation, such as careful decision-making, overcoming difficulties, and resisting temptations, also require the loss of a li- 
mited amount of mental energy or psychological resources, called self-control resources. Ego-depletion is a process in which an individual's self-control resources are consumed in a large amount, and a process in which psychological resources are depleted (Leith \& Baumeister, 1996). The aftereffects mainly include a series of problems manifested by individuals at the cognitive, emotional, and behavioral levels.

Since Baumeister et al. (1998) found that Ego-depletion leads to a decline in individual cognitive levels, a large number of studies have found that Ego-depletion not only affects the individual's basic cognitive responses in terms of attention, memory, and thinking, but also affects individuals. Social cognitive process. Ego-depletion can also lead to reduced persistence and accuracy of individual thinking (Baumeister et al., 1998), reduced fluency in speech and image cognition (Schmeichel et al., 2006), logical reasoning inference, and reduced accuracy in reading comprehension (Schmeichel et al., 2003). Moreover, the individual's cognitive process and emotional process are often the premise and basis of external behavioral expression. Therefore, a path of Ego-depletion affecting individual behavior may be achieved by directly changing the individual's cognitive process and emotional process (Chen, $\mathrm{Xu}$, Yang et al., 2011).

\subsection{Dual-Processing Theory}

In the field of cognitive psychology, dual processing theorists (Sloman, 1996; Stanovich \& West, 1998; Epstein \& Pacini, 1999; Evans, 2012) argue that there are two completely hidden in human thinking, reasoning, and decision making. Different cognitive processes. The dual processing theory is widely used in the field of cognitive psychology and social psychology. Many theorists describe the double processing process as two different cognitive systems and have different names.

The dual-process theory starts from the information processing process and elaborates on the mechanism of information selection preference. The most representative of these are the elaboration likelihood model (ELM) and the heuristic system model (HSM).

The fine processing possibility model believes that individuals deal with persuasion information through two relatively independent paths, one is the central path mode, which is to make the decision after fine processing of the information content; the other is the edge path mode, i.e. Some simple background clues to information (such as emotional information, attractiveness, and source credibility, etc.) are processed to make decisions.

The heuristic-systematic processing model is largely consistent with the fine processing possibility model, but emphasizes the influence of motivation and cognitive processing power on individual information processing (Chaiken, Liberman, \& Eagly, 1989), among which, Machining is spontaneous, parallel, and heuristic execution does not rely on advanced cognitive control systems. When the heuristic stimulus is triggered, heuristic processing is performed. This execution is fast, emotional. The associative, implicit learning process does not depend 
on cognitive processing power. Unlike heuristics, systemic processing is serial and slow, requiring cognitive effort. When systemic processing dominates, decision makers perform comprehensive and in-depth processing and analysis of information.

Appeal refers to what kind of content and expression to persuade consumers, it has to solve the problem of "what to say" and "how to say" (Wang \& Guan, 2009), generally refers to the desire And needs, in order to win the attention and resonance of the audience, and ultimately achieve the purpose of inducing the audience to shop, and emotional appeal and rational appeal are the two basic ways of information appeal.

Advertising appeal type refers to the conscious use of various strategies by advertisers to stimulate potential consumers to further collect information on products, to form or change attitudes and perceptions of the products, and ultimately to purchase behavior (Amir, 2000). According to the different points of appeal, advertisements are mainly divided into rational appeal advertisements and emotional appeal advertisements (Ding \& Kang, 2007). Sensual appeals to the audience, adopting a emotional persuasion method, grasping the emotional needs of the audience, appealing to the audience that the product can meet the needs of self-esteem and self-confidence, stimulating the audience's emotions, and affecting the audience's impression of the advertisement and products. Therefore, it produces a huge emotional appeal and influence; rational appeal is based on the function and characteristics of the product, adopts a rational persuasion method, and directly discusses the characteristics and strengths of the product directly, so that the audience can pass the concept, judgment, Reasoning and other thinking processes, making decisions sensibly.

According to the dual processing theory, when an individual's cognitive processing ability is low or the motivation is low, since the individual with low cognitive processing resources does not have enough ability to process complex cognitive information, the individual's systematic analysis of information is suppressed and inspired. The processing (or edge path) mode predominates, when the emotional information is more convincing to the individual; when the individual's cognitive processing ability is high or the motivation is high, the system processing (or central path) mode pair is adopted. Information is processed, and individuals with high cognitive processing resources have the ability to process complex cognitive information. Therefore, ads for rational appeal often persuade the audience through systematic processing (or central path) models (Zhou \& Jin, 2006).

\section{Assumptions}

Based on the previous academic literature on time landmarks, ego-depletion and advertising appeals, this study combines the methods of qualitative research and quantitative research in combination with the marketing phenomenon in daily life to explore the perception of time landmarks and the preferences of consumers for different advertising appeals. The influence, as well as its intrinsic psy- 
chological mechanism, the role of ego-depletion perception, also explores the moderation of product involvement.

\subsection{Effect of Activation of Different time Landmarks on Consumer advertising Appeal Type Preferences}

Time is one of the most important environmental variables and has a significant impact on consumer perception and behavior (Goldenberg et al., 2000), and context determines whether emotional or cognitive pathways are most convincing to consumers (Pham \& Avnet, 2004). The time landmarks is an environmental clue in the daily shopping life of consumers. Activation of the fresh time landmarks or ending time landmarks can cause different psychological perceptions of consumers, which may affect consumers' preference for emotional or rational appeal.

Individuals who activate the fresh time landmarks will have more psychological resources than the ending time landmarks. Since individuals need to accumulate enough physical and mental energy to self-regulate and control (Baumeister et al., 2002), their perception of self-resources is weaker when they activate their perception of ending-time landmarks. Therefore, compared with the fresh time landmarks, when people activate the perception of the ending time landmarks, people's psychological resource exhaustion perception will be significantly enhanced (Zhang Ziqi, Pang Wei, Liu Xiaomei, 2017).

When people perceive that psychological resources are at a lower level, individuals may prefer information about emotional appeals; and when people perceive that psychological resources are at a higher level, individuals may prefer information of rational appeals. Because of the emotional approach to information processing, cognitive information processing methods need to consume more psychological resources and cognitive resources (Hofmann, Schmeichel, \& Baddeley, 2012), and when people's psychological resources are limited, people will make choices based on feelings (Shiv \& Fedorikhin, 1999). Therefore, we propose the following assumptions:

H1: The time landmarks affects the consumer's preference for the type of advertising appeal.

According to the cognitive dual processing theory, when the individual's perception of the fresh time landmarks is activated, the individual's psychological resources are relatively sufficient, and the individual's cognitive processing ability will be relatively higher. At this time, people should prefer cognitive information processing. And rational appeal advertising is more effective for individuals with high cognitive processing ability (Zhou \& Jin, 2006), so when the fresh time landmarks is activated, people prefer rational appeal advertising. Therefore, we propose the following hypothesis:

H1a: Consumers who activate the fresh time landmarks prefer a rational advertising appeal compared to the ending time landmarks.

When the individual's perception of the ending time landmarks is activated, the individual's psychological resources are relatively less, and the individual's 
cognitive processing ability is also relatively lower. At this time, people should prefer to choose emotional information processing methods because of low cognitive processing resources. Individuals do not have the ability to process complex cognitive information, and emotional appeals are more closely matched to individuals with low cognitive processing capabilities (Hong et al., 2004), so when activation of ending-time landmarks, people prefer emotional appeals. Therefore, we propose the following hypothesis:

H1b: Consumers who activate the ending time landmarks prefer a emotional advertising appeal compared to the fresh time landmarks.

\subsection{Mediating Role of Ego-Depletion}

People often use contextual cues to inform or explain their internal state. Individuals are affected by situational attribution, and perceived ego-depletion states may differ from actual ego-depletion. Clarkson, Hirt et al. (2010) argue that perception of loss is an important component of resource loss, and that perception of exhaustion depends not only on the actual consumption state of the individual, but also on the contextual attribution information provided. Therefore, this paper believes that time landmarks as a situational factor will affect people's Ego-depletion, which will make consumers have different preferences for different advertising appeals.

By comparing individual cognitive and behavioral differences at different time points, individuals at the beginning of time have more self-control than normal time points (Kouchaki \& Smith, 2014), meaning individuals who are at the beginning of time landmarks The perception of loss is lower. This is because ego-depletion is a process in which the individual's self-control resources are consumed a lot, and the psychological resources are depleted. Compared with the low self-control level, individuals with higher self-control levels have more self-control resources (Baumeister, 1996). Therefore, the Ego-depletion is also lower. In addition, Shang, Pang, \& Liu (2017) and others believe that compared with the fresh time landmarks, when people activate the perception of the ending time landmarks, people's perceived psychological resource exhaustion is significantly greater. And studies by Job, Dweck, \& Walton (2010) confirm that mental fatigue is a mediator of the self-depleting effect. Therefore, compared with the activation fresh time landmarks, when the ending time landmarks is activated, people's perception of psychological resource exhaustion is greater, and the perception of ego-depletion is higher.

Different types of advertising appeals are preferred when individuals are at different levels of Ego-depletion. Specifically, individuals with higher Ego-depletions prefer emotional appeals compared to low Ego-depletions; individuals with lower Ego-depletions prefer rational appeals compared to high Ego-depletions. This is because Ego-depletion affects people's cognitive dual processing system. Individuals with high ego-depletion tend to be heuristic, fast, emotional, and associative processing systems. Individuals with low ego-depletion tend to be serial and slow. A rapid processing system that requires cognitive effort (Pocheptsova 
et al., 2009; Burkley et al., 2008; Fennis \& Janssen, 2010). Moreover, in the relationship between ego-depletion and information type preference, Lu \& Sinha (2017) have experimentally verified that compared with the non-loss group, when the subject completes the loss task and leads to the loss of self-regulating resources, more attention will be paid to the emotional information. Not rational information.

In summary, this paper believes that the activation of different time landmarks will affect consumers' preference for the type of rational or emotional advertising appeals, because different time landmarks have different effects on consumers' Ego-depletion perception, thus affecting for the type of rational or emotional advertising appeals, we propose the following assumptions:

$\mathrm{H} 2$ : Ego-depletion plays a mediating role in the impact of time landmarks on consumer advertising appeal type preferences.

\section{Experimental}

\subsection{Experimental One}

The purpose of experiment 1 is to verify the influence of activation of different time landmarks on consumers' different types of advertising appeals, and to explore whether consumers will have different evaluations and effects on advertisements of two types of appeals under the stimulus of activation of different time landmarks. Investigate the mediating role of Ego-depletion.

This experiment was designed with a 2 (time landmarks: fresh time landmarks VS ending time landmarks) ${ }^{*}$ (advertising appeal type: emotional advertisement vs rational advertisement). Distributed through the network, a total of 223 participants were invited to participate in the experiment. After removing 33 subjects who did not complete the experiment according to the experimental requirements, a total of 190 valid samples were collected. Their average age is 29.85 years old, of which males account for $48.4 \%$, women account for $51.6 \%$, students account for $33.7 \%$, and employed persons account for $66.3 \%$. Because there are no significant effects on demographic factors such as age and gender, subsequent data analysis is not taken into account.

Participants were randomly assigned to the imaginary situation of the fresh time landmarks and the ending time landmarks. The experiment was conducted on the basis of testing the imagination of the subjects, so the subjects did not understand the purpose of the experiment. The experiment selected the hair dryer as the display product, and the sensibility and rational slogan about the hair dryer were randomly assigned to the participants. The experiment consists of two seemingly unrelated tasks. The first task is the "imagination test", which is used to activate the participants' perception of different time landmarks. The second task is "product slogan survey" for measurement. The attitude of the participants on the slogan.

Taking the advertising attitude as the dependent variable, the variance analysis of 2 (time landmarks: fresh time landmarks VS ending time landmarks) ${ }^{\star} 2$ (ad- 
vertising appeal type: emotional advertisement vs rational advertisement) is performed.

According to the experimental results, we found that the time landmarks ( $\mathrm{F}$ $(1,186)=0.233, p=0.630)$ and the type of advertising appeal $(\mathrm{F}(1,186)=0.028$, $p=0.867)$ had no significant effect on the advertising attitude. The interaction of the time landmarks and the type of advertising appeal has a significant impact on the advertising attitude $(\mathrm{F}(1,186)=11.298, p=0.001)$.

Because the interaction effect is significant, the simple effect analysis is carried out. The results show that for the participants who activate the fresh time landmarks, the score of the advertising attitude of rational advertising appeal is significantly higher than that of the emotional advertising appeal ( $\mathrm{M}$ rational = $5.36>\mathrm{M}$ sensibility $=4.82, \mathrm{~F}(1,189)=6.43, p=0.012)$. For the subjects who started the ending time landmarks, the score of the advertising attitude of the emotional advertisement appeal was significantly higher than that of the rational advertisement appeal $(\mathrm{M}$ emotional $=5.26>\mathrm{M}$ rational $=4.77, \mathrm{~F}(1,189)=5.08$, $p=0.025)$. So $\mathrm{H} 1, \mathrm{H} 1 \mathrm{a}$ and $\mathrm{H} 1 \mathrm{~b}$ are established.

According to the mediation effect analysis program proposed by Zhao et al. (2010), the Bootstrap method proposed by Preacher et al. (2007) and Hayes (2013) is used for mediation test. The model 15 is selected for testing. The sample size is selected as 5000 and the confidence is set to $95 \%$. The results showed that with the advertising attitude as the dependent variable, the mediating effect of Ego-depletion was significant (95\% CI: LLCI $=-0.5699$, ULCI $=-0.0964$, excluding 0), which indicated that Ego-depletion perception was different in time landmarks and consumers. The influence of the type preference of appeals has played a mediating role. Therefore, $\mathrm{H} 2$ is established.

\subsection{Experimental Two}

Experiment 2 has two purposes. First, we use different manipulation methods for the perception of time landmarks. In the year, let the participants perceive the beginning and end of the year, and re-validate the impact of time landmarks on advertising appeal preferences to confirm the effect. The stability. Second, we again verify the psychological mechanisms behind this effect and control the potential impact of emotions.

This experiment was designed with a 2 (time landmarks: fresh time landmarks VS ending time landmarks) ${ }^{\star} 2$ (advertising appeal type: emotional advertisement vs rational advertisement). In the name of an advertising company's research on consumer opinions, we distributed 227 participants to participate in the experiment, and collected valid samples after removing 35 participants who did not complete the experiment according to the experimental requirements. Share. Their average age is 29.6 years old, of which males account for $39.1 \%$, women account for $60.9 \%$, school students account for $27.1 \%$, and employed people account for $72.9 \%$. Because there are no significant effects on demographic factors such as age and gender, subsequent data analysis is not taken in- 
to account.

Participants were randomly assigned to the experimental group with the fresh time landmarks and the ending time landmarks. The subjects in the fresh time group were tested on January 1 and the ending time group subjects were tested on December 31. In order to prevent the participants from inspecting the purpose of the experiment, let them fill in the date of the day on the grounds that the experiment should continue for several days. The experiment selected the vacuum cleaner as the display product, and the sensibility and rational slogan about the vacuum cleaner were also randomly assigned to the participants to watch. Finally, the product slogan survey was conducted in the name of the research of the advertising company to measure the attitude of the participants on the slogan.

Taking the advertising attitude as the dependent variable, the variance analysis of 2 (time landmarks: fresh time landmarks VS ending time landmarks) ${ }^{\star 2}$ (advertising appeal type: emotional advertisement vs rational advertisement) is performed.

According to the experimental results, we found that the time landmarks ( $\mathrm{F}$ $(1,188)=2.235, p=0.137)$ and the type of advertising appeal $(\mathrm{F}(1,188)=0.450$, $p=0.503$ ) had no significant effect on the advertising attitude. The interaction of the time landmarks and the type of advertising appeal has a significant impact on the advertising attitude $(\mathrm{F}(1,188)=30.303, p=0.00)$.

Because the interaction effect is significant, a simple effect analysis is further performed.

For the participants who activated the fresh time landmarks, the score of the advertising attitude of rational advertising appeal was significantly higher than that of the emotional advertising appeal $(\mathrm{M}$ rationality $=5.50>\mathrm{M}$ emotional $=$ 4.63, $\mathrm{F}(1,191)=12.4, p=0.001)$. For the subjects who started the ending time landmarks, the score of the advertising attitude of the emotional advertising appeal was significantly higher than that of the rational advertising appeal (M-emotional $=5.35>\mathrm{M}$ rationality $=4.23, \mathrm{~F}(1,191)=20.65, p=0.000)$. So H1, H1a and $\mathrm{H} 1 \mathrm{~b}$ are established.

According to the mediation effect analysis program proposed by Zhao et al. (2010), the Bootstrap method proposed by Preacher et al. (2007) and Hayes (2013) is used for mediation test. The model 15 is selected for testing. The sample size is selected as 5000 and the confidence is set to $95 \%$. The results show that with the advertising attitude as the dependent variable, the mediating effect of Ego-depletion is significant (95\% CI: LLCI $=-1.1273$, ULCI $=-0.2474$, excluding 0), which indicates that Ego-depletion perception is different in time landmarks and consumers. The influence of the type preference of appeals played a mediating role, and it was tested again that $\mathrm{H} 2$ was established. Similarly, with the advertising attitude as the dependent variable, the mediating effect of emotion is not significant (95\% CI: LLCI $=-0.2590$, ULCI $=-0.0119$, including 0 ), which excludes the potential explanation of emotions. 


\section{Research Conclusions}

Time landmarks are an environmental clue that is common in people's daily shopping life. Whether it is a natural time-based time landmarks or a situational time landmarks, it has an important impact on consumer perception and behavior (Goldenberg et al., 2000). At the same time, the situation determines whether the emotional or cognitive path is the most convincing to consumers (Pham \& Avnet, 2004). In the past, the research on the preference of advertising appeal type ignores the influence of the environmental cues often in the advertising information on the preference of advertising appeals, which in turn affects consumers' different attitudes toward advertising appeals. This study is to explore the influence of the perception of different time landmarks on the preference of consumers' advertising appeals, and to study the role of Ego-depletion perception in this process, which provides a relevant explanation mechanism for this phenomenon, and also analyzes it. The psychological mechanism behind its phenomenon. In the process, several conclusions have also been drawn.

First, the time landmarks affects consumers' preferences for the type of advertising appeal.

In the past, the research on time landmarks mainly focused on its influence on self-control behavior, health choices, and its impact on the real self and the past or future self. In recent years, some scholars have begun to study its impact on product type preferences. Research indicates that this is because the time landmarks will affect the individual's psychological perception, and the individual's mental state and cognitive state will affect their preference for information appeal. However, the predecessors' research on the type preference of advertising appeals is generally from the individual characteristics of consumers (Wang \& Zhang, 2005), or the degree of consumer involvement in products (Pieters et al., 2002), and different product types and brands (Fisher \& Dube, 2003). Li et al. (2015) explores consumers' preferences for the types of advertising appeals, so the impact of consumers' preference on advertising appeals needs to be further studied under different time landmarks. The study concludes that the time landmarks affects consumers' preference for the type of advertising appeal, that is, consumers who activate the fresh time landmarks prefer the rational advertising appeal, while consumers who activate the ending time landmarks prefer the emotional advertising appeal. Rational advertising appeals are best matched with some environmental clues that indicate the fresh time. Sensitive advertising appeals are best matched with some environmental clues indicating the ending time, whether it is a situational time landmarks embedded in the advertisement or in the advertisement. The real time landmarks of the prompt so that the consumer has a better attitude towards the advertisement. To this end, this study explores the impact of time landmarks on consumer preference types preferences through three experiments.

Second, Ego-depletion perception plays a mediating role in the influence of time landmarks on consumer advertising appeal type preferences. 
The time landmarks is a situational clue, and the individual's perceived Ego-depletion state is affected by the situational attribution (Clarkson \& Hirt, 2010). This paper considers that the time landmarks as a situational factor will affect people's Ego-depletion perception. When the time is landmarks, people's perceptions of psychological resource exhaustion are different, and the perception of ego-depletion is also different, which makes consumers have different preferences for different advertising appeals. This is because Ego-depletion affects people's cognitive dual processing systems. Individuals with high ego-depletion tend to heuristically process information, and individuals with low egodepletion tend to systematically process information (Pocheptsova et al., 2009). Advertising, which is a emotional appeal, often persuades the audience through a heuristic processing (or edge path) model, and ads for rational appeal often persuade the audience through a systematic processing (or central path) model (Zhou \& Jin, 2006) because when the subjects are at At the loss state, more attention is paid to inductive information than to rational information (Lu \& Sinha, 2017).

In Experiments 1 and 2, we used experimental methods and different manipulation and stimulation materials to manipulate the time landmarks (freshing time landmarks and ending time landmarks) and advertising appeal types (emotional advertising appeals and rational advertising appeals). The subjects were asked to answer the Ego-depletion-awareness scale, and the results of the data analysis preliminarily verified the hypothesis. At the same time, they also examined the possible effects of other alternative intermediaries. The results obtained were consistent with the hypothesis. These results provide further empirical support for the impact of time landmarks on consumer advertising appeal type preferences. Through these two experiments, we confirmed that the time landmarks has an influence on the type of consumer advertising appeal, and Ego-depletion plays a mediating role.

\section{Theoretical Significance}

The theoretical significance of this research is mainly reflected in:

On the one hand, in the current research on time landmarks, many foreign scholars study the influence of different time markers on people's self-control behavior and their influence on the real self and the past or future self. In addition, some scholars began to study. The impact of different time landmarks on different types of products. In this study, different time landmarks will influence people's different psychological perceptions, explore their influence on the types of advertising appeals, and expand the impact of time landmarks.

On the other hand, although the research on the preference of advertising appeals has been richer, the scholars in the past generally refer to the characteristics of individual consumers, or the involvement of consumers in products, and different product types and brands to explore consumer preferences for advertising appeal types. At present, no scholars have explored the preferences of 
consumers for rational or emotional advertising appeals under different environmental cues from the perspective of other environmental cues in advertising. Therefore, this paper also enriches the premise research on consumers' preference for advertising appeals.

\section{Practical Significance}

The time landmarks is a situational clue that can be seen everywhere in the advertisement information. Some advertisements will prompt the real natural time landmarks in the content (such as prompting the current year/year end, month/month end, etc.), and some advertisements will be interspersed in the content. Implant a situational time landmarks (such as an ad setting in the morning/night, etc.). As a marketing tool that stimulates consumers' desire to purchase and increase sales, how to generate maximum advertising results under a limited marketing budget is one of the issues that all companies are focusing on. The advertising schemes of merchants with sensible advertising appeals and rational advertising appeals emerge in an endless stream. In order to attract more consumers' attention, advertisements need more subtle and precise design.

Combining the previous literature foundation and the conclusions of this study, in order to better enhance the advertising effect of different appeals and improve consumers' attitudes towards different appeal advertisements, in the future, enterprises will activate corresponding time landmarks when advertising of different appeal types to make advertisements. Have a better delivery effect. Specifically, based on the controllability of the time landmarks, when the rational advertisement is placed, the enterprise can select a natural fresh time point (such as Monday, early month, early year, etc.) to activate the fresh time landmarks, and also can embed the scene in the advertisement. Fresh time points (such as early morning sunrise, etc.) to activate the fresh time landmarks; similarly, when placing a emotional advertisement, the company can choose the natural ending time point (such as Friday, end of the month, year-ending, etc.) to activate the ending time landmarks. At the same time, the ending time point (such as night) can be inserted in the advertisement to activate the ending time landmarks.

\section{Research Limitations}

Through literature review and empirical analysis, although the results obtained have initially verified the experimental hypothesis in the paper, there are still many shortcomings.

In the process of trial manipulation, this paper focuses on the impact of the fresh and ending time landmarks on the preferences of consumer advertising appeals, and does not conduct in-depth research on other time landmarks with special characteristics. Therefore, future research hopes to find more timelandmarks and marketing relationship, making time-landmarks research more perfect and rich in marketing applications. 
The single classification criteria used in this study for the type of advertising appeals did not explore whether other types of advertising appeals also have such effects. The classification of emotional advertising appeals and rational advertising appeals will inevitably miss some other commonly used advertising methods, so subsequent research can continue to study from different classification perspectives.

\section{Future Research Prospects}

In the course of this research, some other problems have been derived, aiming to provide relevant research directions for subsequent research.

In addition to the impact of the fresh and ending time landmarks on consumer advertising appeal type preferences, will other special time landmarks also have such an effect? At the same time, in life, advertising appeals are not only in the form of sensibility or rationality, so will the combination of different appeals have different effects on marketing behavior?

Do we have other psychological interpretation mechanisms in exploring the influence of time landmarks on consumer advertising appeal type preferences? Do we still have other boundary conditions in exploring the impact of time landmarks on consumer advertising appeal type preferences?

\section{Fund}

This research was funded by the Ministry of Education Humanities Social Science Foundation (14YJA630099).

\section{Conflicts of Interest}

The author declares no conflicts of interest regarding the publication of this paper.

\section{References}

Alter, A. L., \& Hershfield, H. E. (2014). People Search for Meaning When They Approach a New Decade in Chronological Age. Proceedings of the National Academy of Sciences of the United States of America, 111, 17066-17070. https://doi.org/10.1073/pnas.1415086111

Arstila, V., \& Lloyd, D., Eds. (2014). Subjective Time: The Philosophy, Psychology, and Neuroscience of Temporality. Cambridge, MA: MIT Press. https://doi.org/10.7551/mitpress/8516.001.0001

Barden, J., \& Petty, R. E. (2008). The Mere Perception of Elaboration Creates Attitude Certainty: Exploring the Thoughtfulness Heuristic. Journal of Personality and Social Psychology, 95, 489-509. https://doi.org/10.1037/a0012559

Baumeister, R. F., Bratslavsky, E., Muraven, M. et al. (1998). Ego Depletion: Is the Active Self a Limited Resource? Journal of Personality and Social Psychology, 74, 1252-1265. https://doi.org/10.1037/0022-3514.74.5.1252

Baumeister, R. F., Sparks, E. A., Stillman, T. F. et al. (2008). Free Will in Consumer Behavior: Self-Control, Ego Depletion, and Choice. Journal of Consumer Psychology, 18, 4-13. https://doi.org/10.1016/j.jcps.2007.10.002 
Baumeister, R. F., Twenge, J. M., \& Nuss, C. K. (2002). Effects of Social Exclusion on Cognitive Processes. Journal of Personality and Social Psychology, 83, 817-827. https://doi.org/10.1037/0022-3514.83.4.817

Burkley, E. (2008). The Role of Self-Control in Resistance to Persuasion. Personality and Social Psychology Bulletin, 34, 419-431. https://doi.org/10.1177/0146167207310458

Chaiken, S., Liberman, A., \& Eagly, A. H. (1989). Heuristic and Systematic Information Processing within and beyond the Persuasion Context. Unintended Thought, 212.

Chen, Y. Y., Xu, Y., Yang, H. Z. et al. (2011). Post-Effect Review of Self-Depletion. Journal of Beijing Normal University (Social Science Edition), 6, 14-20.

Clarkson, J. J., Hirt, E. R., Jia, L. et al. (2010). When Perception Is More than Reality: The Effects of Perceived versus Actual Resource Depletion on Self-Regulatory Behavior. Journal of Personality and Social Psychology, 98, 29-46. https://doi.org/10.1037/a0017539

Dai, H., Milkman, K. L., \& Riis, J. (2014). The Fresh Start Effect: Temporal Landmarks Motivate Aspirational Behavior. Social Science Electronic Publishing, 60, 2563-2582.

Ding, J. J., \& Kang, W. (2007). General Theory of Modern Advertising (2nd ed.). Communication University of China Press.

Epstein, S., \& Pacini, R. (1999). Some Basic Issues regarding Dual-Process Theories from the Perspective of Cognitive-Experiential Self-Theory. Dual-Process Theories in Social Psychology, 462-482.

Ersner-Hershfield, H., Garton, M. T., Ballard, K. et al. (2009). Don't Stop Thinking about Tomorrow: Individual Differences in Future self-Continuity Account for Saving. Judgment and Decision Making, 4, 7.

Evans, J. S. B. T. (2012). How Many Dual-Process Theories Do We Need? One, Two, or Many? Two Minds Dual Processes \& Beyond, 33-54.

Fennis, B. M., \& Loes, J. (2010). Mindlessness Revisited: Sequential Request Techniques Foster Compliance by Draining Self-Control Resources. Current Psychology, 29, 235-246. https://doi.org/10.1007/s12144-010-9082-X

Fisher, R. J., \& Dube, L. (2003). Gender Differences in Responses to Emotional Advertising: The Effect of the Presence of Others. Advances in Consumer Research, 30.

Goldenberg, J. L., Mccoy, S. K., Pyszczynski, T. et al. (2000). The Body as a Source of Self-Esteem: The Effect of Mortality Salience on Identification with One's Body, Interest in Sex, and Appearance Monitoring. Journal of Personality \& Social Psychology, 79, 118-130. https://doi.org/10.1037/0022-3514.79.1.118

Grondin, S. (2001). From Physical Time to the First and Second Moments of Psychological Time. Psychological Bulletin, 127, 22-44.

https://doi.org/10.1037/0033-2909.127.1.22

Grondin, S. (2010). Timing and Time Perception: A Review of Recent Behavioral and Neuroscience Findings and Theoretical Directions. Attention, Perception, \& Psychophysics, 72, 561-582. https://doi.org/10.3758/APP.72.3.561

Hetsroni, A. (2000). The Relationship between Values and Appeals in Israeli Advertising: A Smallest Space Analysis. Journal of Advertising, 29, 55-68. https://doi.org/10.1080/00913367.2000.10673617

Hofmann, W., Schmeichel, B. J., \& Baddeley, A. D. (2012). Executive Functions and Self-Regulation. Trends in Cognitive Sciences, 16, 174-180.

https://doi.org/10.1016/j.tics.2012.01.006

Hong, W., Thong, J. Y. L., \& Tam, K. Y. (2004). The Effects of Information Format and Shopping Task on Consumers Online Shopping Behavior: A Cognitive Fit Perspective. 
Journal of Management Information Systems, 21, 149-184.

https://doi.org/10.1080/07421222.2004.11045812

Job, V., Dweck, C. S., \& Walton, G. M. (2010). Ego Depletion-Is It All in Your Head? Implicit Theories about Willpower Affect Self-Regulation. Psychological Science, 21, 1686-1693.

Khan, U., \& Dhar, R. (2007). Where There Is a Way, Is There a Will? The Effect of Future Choices on Self-Control. Journal of Experimental Psychology General, 136, 277. https://doi.org/10.1037/0096-3445.136.2.277

Koo, M., \& Fishbach, A. (2008). Dynamics of Self-Regulation: How (Un)accomplished Goal Actions Affect Motivation. Journal of Personality \& Social Psychology, 94, 183-195. https://doi.org/10.1037/0022-3514.94.2.183

Kouchaki, M., \& Smith, I. H. (2014). The Morning Morality Effect: The Influence of Time of Day on Unethical Behavior. Psychological Science, 25, 95-102. https://doi.org/10.1177/0956797613498099

Leith, K. P., \& Baumeister, R. F. (1996). Why Do Bad Moods Increase Self-Defeating Behavior? Emotion, Risk Taking, and Self-Regulation. Journal of Personality \& Social Psychology, 71, 1250-1267. https://doi.org/10.1037/0022-3514.71.6.1250

Li, G., Wang, X., Jiang, H. et al. (2015). Experimental Study on the Matching Effect of Advertising Appeals and Brand Preference. Psychological Research, 8, 60-65.

Lu, F., \& Sinha, J. (2017). Speaking to the Heart: Social Exclusion and Reliance on Feelings versus Reasons in Persuasion. Journal of Consumer Psychology, 27, 409-421.

Muraven, M., \& Slessareva, E. (2003). Mechanisms of Self-Control Failure: Motivation and Limited Resources. Personality \& Social Psychology Bulletin, 29, 894-906. https://doi.org/10.1177/0146167203029007008

Oettingen, G., Mayer, D., Timur, S. A. et al. (2009). Mental Contrasting and Goal Commitment: The Mediating Role of Energization. Personality \& Social Psychology Bulletin, 35, 608-622. https://doi.org/10.1177/0146167208330856

Pham, M. T., \& Avnet, T. (2004). Ideals and Oughts and the Reliance on Affect versus Substance in Persuasion. Journal of Consumer Research, 30, 503-518. https://doi.org/10.1086/380285

Pieters, R., Warlop, L., \& Wedel, M. (2002). Breaking through the Clutter: Benefits of Advertisement Originality and Familiarity for Brand Attention and Memory. Management Science, 48, 765-781. https://doi.org/10.1287/mnsc.48.6.765.192

Pocheptsova, A., Amir, O., Dhar, R. et al. (2009). Deciding without Resources: Resource Depletion and Choice in Context. Journal of Marketing Research, 46, 344-355. https://doi.org/10.1509/jmkr.46.3.344

Ross, M. (1989). Relation of Implicit Theories to the Construction of Personal Histories. Psychological Review, 96, 341-357. https://doi.org/10.1037/0033-295X.96.2.341

Schmeichel, B. J., Demaree, H. A., Robinson, J. L. et al. (2006). Ego Depletion by Response Exaggeration. Journal of Experimental Social Psychology, 42, 95-102. https://doi.org/10.1016/j.jesp.2005.02.005

Schmeichel, B. J., Vohs, K. D., \& Baumeister, R. F. (2003). Intellectual Performance and Ego Depletion: Role of the Self in Logical Reasoning and Other Information Processing. Journal of Personality \& Social Psychology, 85, 33-46. https://doi.org/10.1037/0022-3514.85.1.33

Shang, Z., Pang, W., \& Liu, X. (2017). The Impact of Time Landmarks on Consumers' Positive Fantasy and Risk-Based New Product Preference. Journal of Marketing Science, 13, 39-55. 
Shiv, B., \& Fedorikhin, A. (1999). Heart and Mind in Conflict: The Interplay of Affect and Cognition in Consumer Decision Making. Journal of Consumer Research, 26, 278-292. https://doi.org/10.1086/209563

Sloman, S. A. (1996). The Empirical Case for Two Systems of Reasoning. Psychological Bulletin, 119, 3-22. https://doi.org/10.1037/0033-2909.119.1.3

Stanovich, K. E., \& West, R. F. (1998). Individual Differences in Rational Thought. Journal of Experimental Psychology: General, 127, 161-188. https://doi.org/10.1037/0096-3445.127.2.161

Wang, P., \& Zhang, G. (2005). The Influence of Advertising Communication and People's Product Confidence. Psychological Science, 28, 614-618.

Wang, W., \& Guan, Y. (2009). Modern Advertising Psychology(2nd ed.).

Zhou, X., \& Jin, Z. (2006). The Effect and Mechanism of Emotional Advertising. Advances in Psychological Science, 14, 126-132. 